\title{
Inflammation and Vascular Injury as the Basis of COVID-19 Skin Changes: Preliminary Analysis of 23 Patients from the Literature
}

This article was published in the following Dove Press journal: Clinical, Cosmetic and Investigational Dermatology

\author{
Yue Zheng* \\ Zijian Gong (D* \\ Jian Chen \\ Yao Lin \\ Yufang Liu \\ Dermatology Department, Third \\ Affiliated Hospital of Sun-Yat Sen \\ University, Guangzhou, People's Republic \\ of China
}

*These authors contributed equally to this work
Correspondence: Yue Zheng

Dermatology Department, Third

Affiliated Hospital of Sun-Yat Sen

University, Guangzhou 510630, People's

Republic of China

Email benbenzhu-II@I63.com
Background: COVID-19 can affect various organ systems including the skin. Cutaneous manifestations of COVID-19 in infected patients are poorly characterized.

Objective: To summarize retrospectively the skin features of COVID-19 infection and to analyze the skin rash incidence rate, clinical onset time, cutaneous manifestations, pathological characteristics and relationship with the novel coronavirus pneumonia severity.

Methods: The literature up to Sep 20, 2020, were searched and analyzed. Information on clinical features including skin manifestations, disease severity, stage and onset day, and cutaneous pathological characteristics was extracted. Data were analyzed using descriptive non-parametric statistics. For categorical data, the number and percentage of patients are presented. A Spearman correlation test was used to analyze the associations between rash type, rash onset and severity of COVID-19. All statistical analysis was performed with IBM SPSS software (version 20) using two-tailed tests. P values $<0.05$ were considered statistically significant.

Results: Twenty-three cases of COVID-19 patients with cutaneous manifestations from seven reports were collected. Inflammatory dermatosis, skin vasculitis and vascular dermatosis were the main lesion types of COVID-19 patients. Microvascular and endothelial cell injury, perivascular lymphocytic infiltrate, thrombosis, extremely dilated vessels and prominent deposits of C5b-9 were the main dermatologic pathological changes. The onset day analysis showed that out of 19 patients, $63.2 \%$ of cutaneous manifestations were within 10 days, $21.1 \%$ in $10-20$ days and $15.8 \%$ were 20 days after the time the patient presented with COVID-19 main symptoms. Spearman rho analysis found no correlation between skin rash type, onset day and COVID-19 severity.

Conclusion: COVID-19 induced skin changes are one of the manifestations of immune responses to the novel coronavirus. Clinical and pathological characteristics were identified as dermal inflammatory reactions and/or skin vascular injury. External or systematic use of anti-inflammatories, protection of blood vessels and circulation-improving medicines should be considered in the skin treatments for novel coronavirus pneumonia patients.

Keywords: COVID-19, skin manifestations, diagnosis, treatment

\section{Introduction}

In late December 2019, a novel coronavirus pneumonia caused by SARS-CoV-2 was reported. ${ }^{1}$ The resulting disease, called Coronavirus Disease 2019 (COVID-19), has rapidly spread and was definedas a global pandemic on March 11, 2020 by the World Health Organization (WHO). 
The main basis of suspected diagnosis of COVID-19 is clinical symptoms, abnormal vital signs and radiologic examination (X-ray, chest CT), etc. The common laboratory examination results are decreased lymphopenia and increased lactate dehydrogenase (LDH). The most common symptoms at onset of COVID-19 illness are fever, cough, and fatigue, while other symptoms include sputum production, headache, hemoptysis, diarrhea, dyspnea, and lymphopenia. ${ }^{2-4}$

At present, the understanding of novel coronavirus is deepening and more and more studies have reported the cutaneous manifestations of COVID-19. However, the relationship between skin rashes and COVID-19 infection is still unclear.

In this study we retrospectively summarized reported cutaneous manifestations in COVID-19 patientsand preliminarily analyzed the skin rash incidence rate, onset time, clinical features, pathological characteristics and relationship with the novel coronavirus pneumonia severity to explore the characteristics and basis of COVID-19 skin changes.

\section{Methods}

We performed a literature search on Pubmed with terms skin rash and COVID-19 on September 20, 2020. Severity of novel coronavirus pneumonia was classified as mild, severe, and acute respiratory distress. ${ }^{5,6}$ Seven reports were found and most of these were case reports. Individual patient data extraction from searched literature mainly included demographic data, comorbidity, rash type, rash onset, and severity of COVID-19. Data were analyzed using descriptive non-parametric statistics. For categorical data, the number and percentage of patients are presented. The Spearman correlation test was used to analyze the associations between rash type, rash onset and severity of COVID-19. All statistical analysis was performed with IBM SPSS software (version 20) using two-tailed tests. $P$ values $<0.05$ were considered statistically significant.

\section{Results}

\section{Clinical Features}

Twenty-three cases of COVID-19 patients with cutaneous manifestations from the reported literature were collected. Inflammatory and vesicular eruptions are the mainlesion types (Figure 1). The skin symptoms reported included exanthema, chickenpox-like vesicles, violaceous macules, livedo reticularis-like eruptions, non-necrotic purpura, chilblain, eruptive cherry angioma, pruritic lesions, retiform purpura, dusky purpuric patches, mildly purpuric reticulated eruptions and other rashes (including cold urticaria and symmetrical drug-related intertriginous and

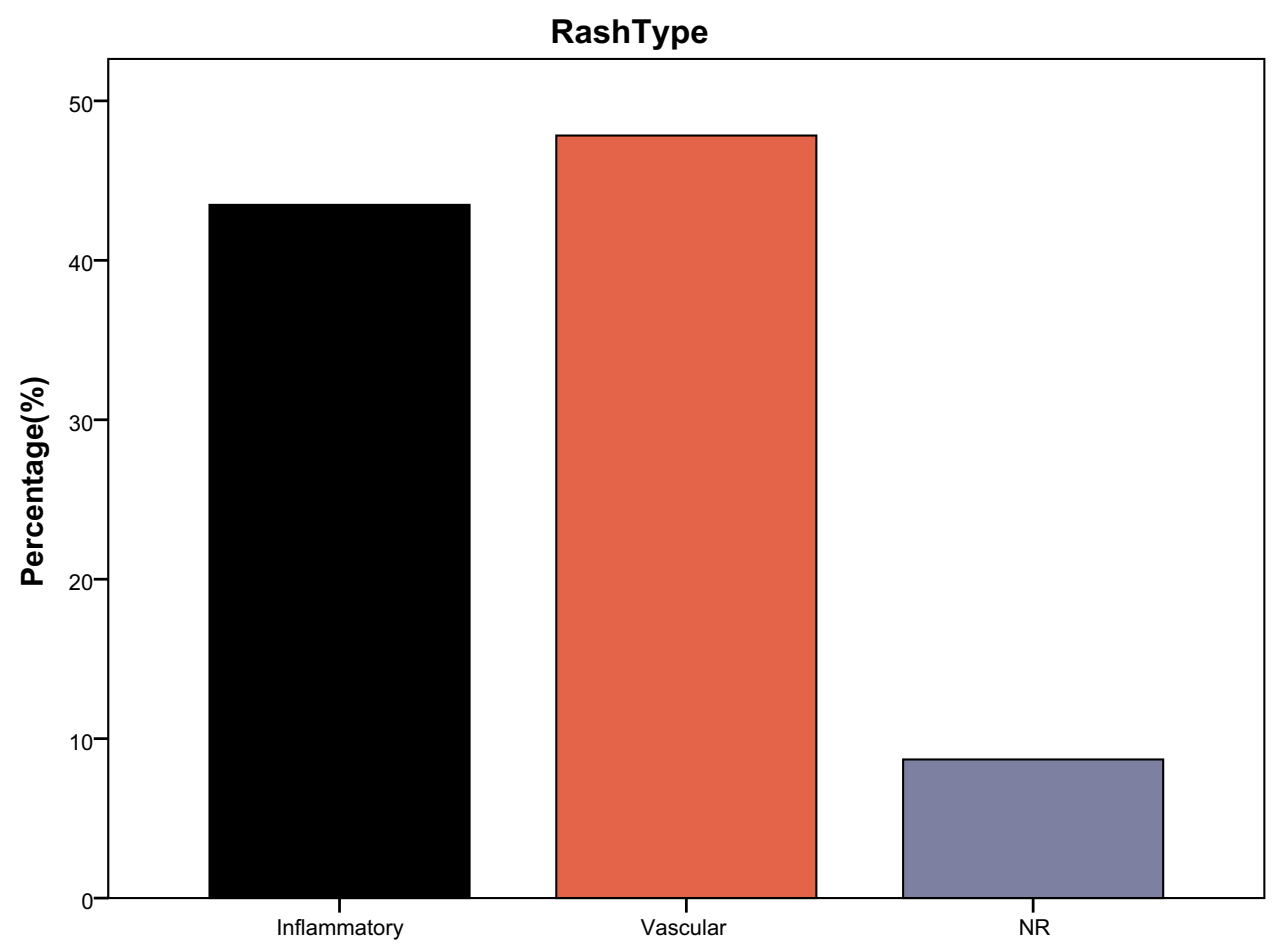

Figure I Clinical features of COVID-19 patients with cutaneous manifestations. Twenty-three cases of COVID-19 patients with cutaneous manifestations from reported literatures were collected. Inflammatory and vesicular eruptions are the main lesion types. 
flexural exanthema (SDRIFE). Urticaria lesions were only reported in two cases. ${ }^{7,8}$ The cutaneous manifestations as an erythematous rash that began on both antecubital fossa and extended on the trunk and axillary folds were only reported in one case. ${ }^{9}$

\section{Correlation Between Cutaneous Manifestations and Novel Coronavirus Pneumonia Symptoms}

The onset day analysis of 19 patients showed that $63.2 \%$ of cutaneous manifestations were found within 10 days of presenting with novel coronavirus pneumonia symptoms such as fever or cough; $21.1 \%$ were found 10-20 days after other symptoms and $15.8 \%$ were found 20 days after other symptoms (Figure 2).

Disease stage of 10 patients with cutaneous manifestations was reported, of which $20 \%$ were patients with mild novel coronavirus pneumonia, 50\% with severe and $30 \%$ with acute respiratory distress (Figure 3). Spearman rho analysis found no correlation between skin rash type, onset day and COVID-19 severity (Table 1).

\section{Pathological Characteristics}

Microvascular and endothelial cell injury, perivascular lymphocytic infiltrate, thrombosis, extremely dilated vessels and prominent deposits of C5b-9 were the main dermatologic pathological changes of COVID-19 patients. The prominent pathological characteristics were inflammatory infiltration, vasculitis, vascular damage and prominent deposits of C5b-9.

\section{Discussion}

COVID-19 can affect different organ systems, probably including the skin. From the early days of the pandemic, COVID-19 has been reported to be linked with multiple different types of skin involvement. Kubanovet al. summarized 46 articles' data with a pooled total of 997 unique patients from 9 countries and found that the skin manifestations frequency was up to $20.45 \% .{ }^{10}$ Galván Casaset al. reported the skin lesions encountered during the COVID19 epidemic in France, and identified that skin symptoms started a few days after first COVID-19 general symptoms and mainly included erythematous rash, urticaria and chickenpox-like lesions. By reviewing the current published literature, Elmas revealed that the cutaneous manifestations of COVID-19 included urticarial, maculopapular, varicellalike, purpuric, livedoid, and thrombotic-ischemic rashes. ${ }^{11}$
There are studies that classify the skin changes of COVID-19 according to the features of skin lesions. Galván Casaset al. conducted a rapid prospective nationwide analysis in Spain and suggested that cutaneous manifestations of COVID-19 might be classified as acral areas of erythema with vesicles or pustules, other vesicular eruptions, urticarial lesions, maculopapular eruptions and livedo or necrosis based on the study. ${ }^{1}$ Marzanoet al. divided the reported cutaneous lesions into six main clinical patterns (urticarial rash, confluent erythematous-maculopapularmorbilliform rash, papulovesicular exanthem, chilblainlike acral pattern, livedo reticularis/livedo racemosa-like pattern and purpuric "vasculitic" pattern) and suggested that these six patterns can be merged into two main groups: inflammatory and exanthematous and the vasculopathic and vasculitic lesions. $^{12}$

We reviewed and summarized the cutaneous manifestations associated with COVID-19 and found that inflammatory dermatosis, skin vasculitis and vascular dermatosis were the main lesions types which presented as exanthema, chickenpox-like vesicles, violaceous macules, livedo, nonnecrotic purpura, chilblain, eruptive cherry angioma (sudden onset of multiple small vascular proliferations), pruritic lesions, retiform purpura, dusky purpuric patches, mildly purpuric reticulated eruptions and other rashes. ${ }^{1,9,13-17}$ Urticarial lesions as cold urticaria were only reported in one case. ${ }^{13}$ Through statistical analysis, we found no correlation between rash type, onset day and disease severity.

Inflammatory skin manifestations in COVID-19 infected patients were in varied forms. Bouaziz reported inflammatory lesions in 7 patients manifesting as exanthema, chickenpox-like vesicles and cold urticaria. ${ }^{13}$ Estébanezet al. reported a patient who presented pruritic lesions on both heels 13 days after positive test of COVID19. ${ }^{14}$ Zengarini et al. reported a 67-year-old Caucasian patient who presented a moderately itching erythematous confluent rash which appeared with a recurrence of fever one month after COVID-19 infection. ${ }^{15}$

Vascular lesions were reported in seven COVID-19 patients in France as violaceous macules with "porcelainlike" appearance, livedo, non-necrotic purpura, necrotic purpura, chilblain appearance with Raynaud's phenomenon, chilblain and eruptive cherry angioma. ${ }^{13}$ Youngreported a 68-year-old critically ill man with COVID-19 who presented an ulcerated purpuric plaque with retiform/livedoid borders. ${ }^{18}$ Diaz-Guimaraenset al. reported a patient with severe acute respiratory syndrome caused by COVID-19 in Spain who presented confluent 


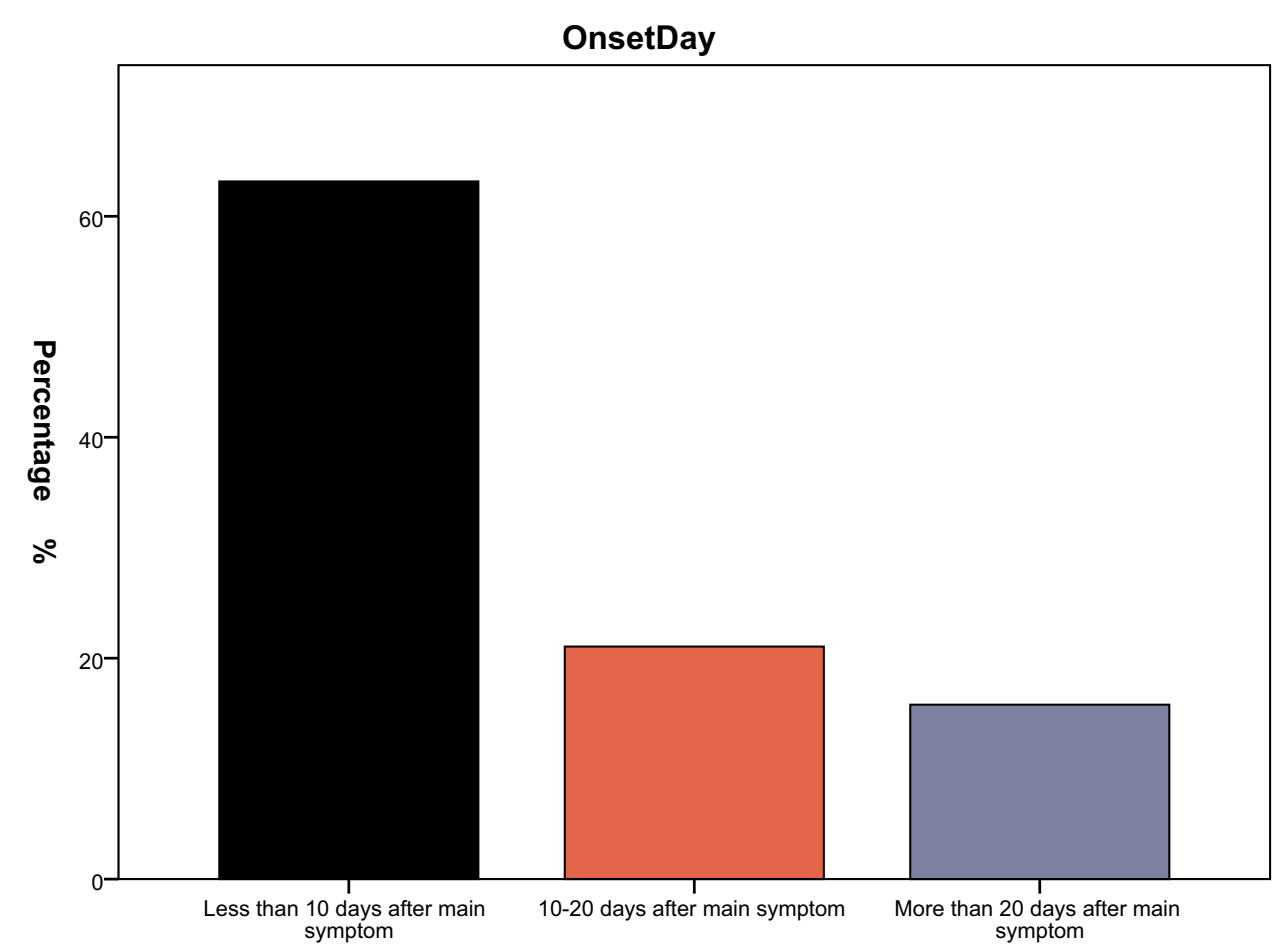

Figure 2 63.2\% of cutaneous manifestations were found within 10 days of patients presenting with novel coronavirus pneumonia symptoms such as fever or cough. $21.1 \%$ were found 10-20 days after other symptoms and $15.8 \%$ were found 20 days after other symptoms.

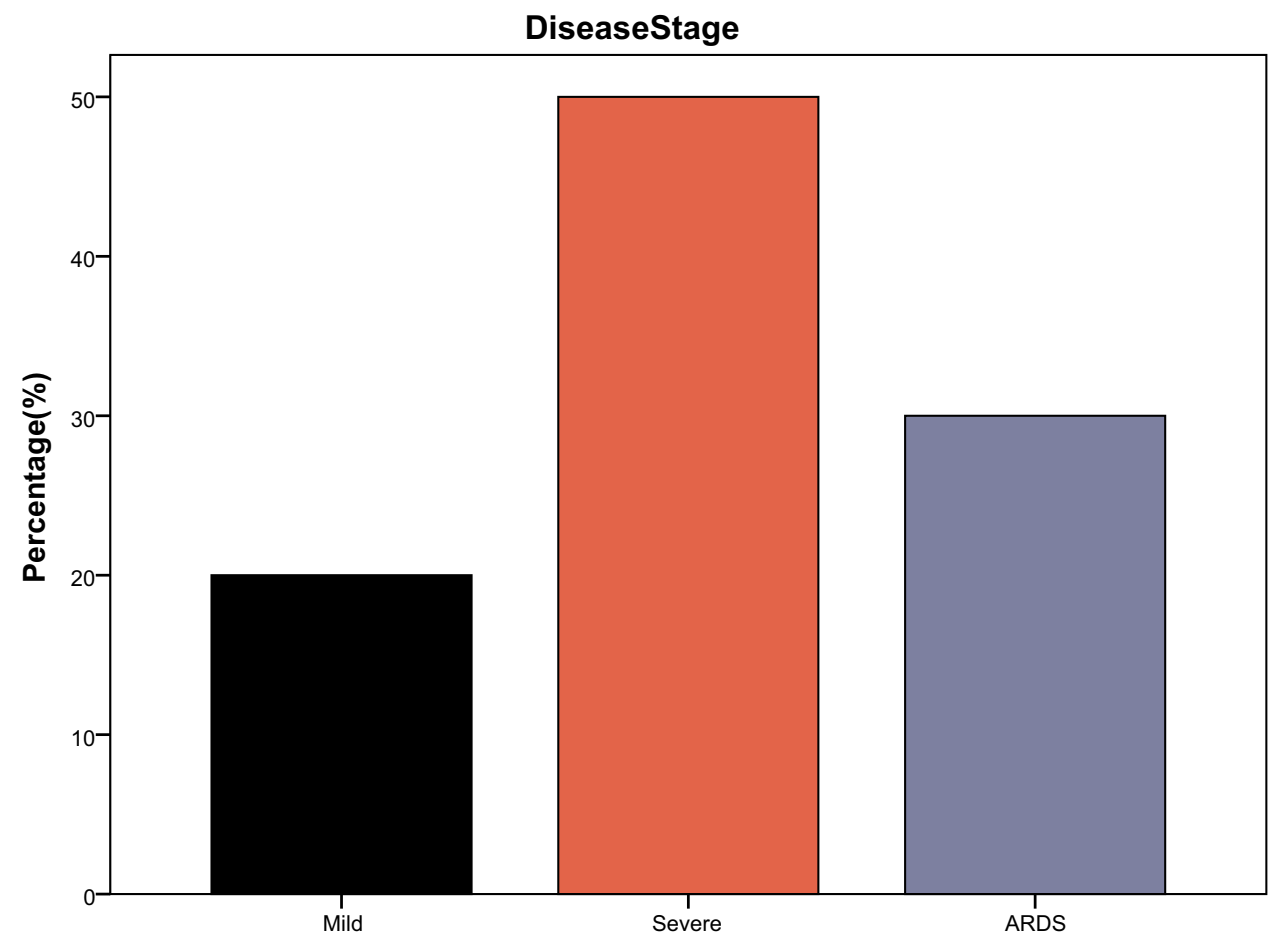

Figure 3 Cutaneous manifestations in COVID-19 patients distributed as $20 \%$ with mild novel coronavirus pneumonia, $50 \%$ with severe and $30 \%$ with acute respiratory distress. 
Table I Spearman Rho Analysis of Skin Rash Type, Onset Day and COVID-I 9 Severity

\begin{tabular}{|c|c|c|c|c|c|}
\hline & & & Rash Type & Onset Day & Disease Stage \\
\hline \multirow[t]{3}{*}{ Spearman's rho } & Rash Type & $\begin{array}{l}\text { R } \\
\text { Sig. (Two Tailed) } \\
\text { N }\end{array}$ & $\begin{array}{l}1.000 \\
23\end{array}$ & $\begin{array}{l}0.348 \\
0.145 \\
19\end{array}$ & $\begin{array}{l}0.436 \\
0.208 \\
10\end{array}$ \\
\hline & Onset Day & $\begin{array}{l}\text { R } \\
\text { Sig. (Two Tailed) } \\
\text { N }\end{array}$ & $\begin{array}{l}0.348 \\
0.145 \\
19\end{array}$ & $\begin{array}{l}1.000 \\
19\end{array}$ & $\begin{array}{l}0.453 \\
0.259 \\
8\end{array}$ \\
\hline & Disease Stage & $\begin{array}{l}\text { R } \\
\text { Sig. (Two Tailed) } \\
\text { N }\end{array}$ & $\begin{array}{l}0.436 \\
0.208 \\
10\end{array}$ & $\begin{array}{l}0.453 \\
0.259 \\
8\end{array}$ & $\begin{array}{l}1.000 \\
10\end{array}$ \\
\hline
\end{tabular}

erythematous macules, papules, and petechiae in a symmetric peri-flexural distribution. ${ }^{16}$ Livedo reticularislike eruptions which are thought to be secondary to COVID-19-induced thrombotic vasculopathy have been reported in the USA. ${ }^{19,20}$ Perniosis-like acral cutaneous lesions ("COVID TOES") in two asymptomatic patients diagnosed with COVID-19 were reported from Kuwait. ${ }^{21}$ Retiform purpura with surrounding inflammation on the buttocks and livedo rashes on the lower extremities, palmar and plantar was reported by Cynthia Magro et al. in USA. $^{17}$

The pathological changes of skin lesions in COVID-19 patients are mainly concentrated in two types: one is the skin immune inflammatory reaction which is characterized by the infiltration of inflammatory cells in dermis, mainly lymphocytes; the other is vascular damage which is characterized by vasculitis, structural damage of vascular endothelium and walls and microvascular embolism. DiazGuimaraens et al. reported the pathology changes as red cell extravasation, dermal papillary edema, and scattered dyskeratotic keratinocytes. ${ }^{16}$ Zengarini et al. reported that slight superficial perivascular lymphocytic infiltrate, extremely dilated vessels in the papillary and mid dermis were found in itching erythematous confluent lesion pathology. ${ }^{15}$ Magro et al. found complement-mediated microvascular injury in the lungs and/or skin of five individuals with severe COVID-19. ${ }^{17}$

Some researchers revealed that similar to SARS-CoV, COVID-19 also uses the angiotensin-converting enzyme 2 (ACE2) receptor to invade human alveolar epithelial cells. $^{22}$ Although remaining in controversial, ${ }^{23}$ several hypotheses have been proposed to date regarding the net effect of angiotensin-converting-enzyme inhibitors (ACEI) on COVID-19 infections. Based on our knowledge, the relation of skin rashes and concomitant ACE inhibitors intake for HBP has been seldom reported. Dermatologists are encouraged to report any available data regarding the relationship between ACEI and skin changes in COVID19 patients.

The pathogenesis of skin rash caused by viral infection includes allergic reaction to viral components, vasculitis induced by viral infection, and dermatomal direct damage by viruses. If the skin structure maintains its integrity, the chance of viral invasion from the skin is essentially nonexistent because skin keratinocytes and fibroblasts do not express ACE2 receptor which is widely distributed in the heart, kidneys, lungs, and testes. Even in a patient who is in the viremic phase, when COVID-19 circulates to all organs including the skin, the quantity of the virus that can colonize and reproduce depends on whether the microenvironment is suitable for viral survival, such as whether there are enough ACE2 receptors on cell surfaces. Therefore, theoretically, it is almost impossible to detect viruses in skin lesions and there have been no reports of positive viral detection from normal skin and skin lesions including vesicles content in COVID-19 patients. The mechanisms of cutaneous manifestation in novel coronavirus pneumonia patients are usually a manifestation of immune responses to COVID-19 which might be induced by the systemic immune system or skin immune system.

High blood levels of cytokines and chemokines were detected in COVID-19 patients which included Interleukin (IL, IL1- $\beta$, IL-1RA, IL-7, IL-8, IL-9, IL-10), basic fibroblast growth factor-2 (FGF-2), granulocyte-macrophage colonystimulating factor (GMCSF), Interferon-gamma (IFN- $\gamma$ ), platelet-derived growth factor (PDGFB), vascular endothelial growth factor A (VEGFA). High levels of pro-inflammatory cytokines including IL-2, IL-7, IL-10, recombinant colony 
stimulating factor (GCSF), interferon-gamma-induced protein-10 (IP-10), monocyte chemotactic protein-1 (MCP-1), macrophage inflammatory protein-1 $\alpha$ (MIP-1 $\alpha)$, and tumor necrosis factor- $\alpha$ (TNF- $\alpha)$ were found in some severe patients. ${ }^{2,3}$ We proposed the hypothesis that these inflammatory mediators, which are rising in circulation, may cause inflammatory damage to the skin through the skin microcirculation system, thus leading to inflammatory, vasculitis and vascular injury in COVID-19 patients.

In skin, C5b-9 and C4d mediated microvascular injuries were found. ${ }^{16}$ Margo suggested that severe COVID-19 may define a type of catastrophic microvascular injury syndrome mediated by activation of complement pathways and an associated procoagulant state. ${ }^{17}$ This indicated that complement-mediated inflammatory response and vascular injury might play a role in inducing skin changes of COVID-19.

D-dimer is the degradation product of fibrin. The increase of D-dimer level in peripheral blood indicates the existence of hypercoagulability and secondary fibrinolysis. High D-Dimer was reported to associate with maculopapular eruptions. ${ }^{24}$ Increasing D-dimer might be related to the circulatory disorder of the multiple organ system including skin caused by the virus and the pathogenesis of skin changes such as vascular occlusive dermatosis in COVID-19 patients.

Familial clustering of COVID-19 cutaneous manifestations such as maculopapular and urticarial rash has been reported. ${ }^{25,26}$ The histopathology of the varicella-like lesions observed during COVID-19 infections of some patients was suggestive of viral infections. ${ }^{17}$ But the route of SARS-CoV -2 (COVID-19) transmission such as through skin-skin contact, vectors and sexual activity is still under study. ${ }^{27,28}$

In conclusion, COVID-19 induced skin changes are one of the manifestations of immune responses to the novel coronavirus. Clinical and pathological characteristics are identified as dermal inflammatory reactions and/or skin vascular injury. Vigilance and differential diagnoses are necessary when dermatologists meet patients presenting inflammatory skin manifestations and vascular lesions in the COVID-19 pandemic. At present, the treatment for COVID-19 induced skin changes is still not unified. Based on the pathological characteristics we suggestthat external or systematic use of anti-inflammatories, protection of blood vessels and circulation-improving medicines could be considered. Although no correlation were found between skin rash type, onset day and COVID-19 severity, more clinical data are needed to further identify the relationship between the virus and the skin.

\section{Data Sharing Statement}

The de-identified data that support the findings of this study are available from the corresponding author upon reasonable request.

\section{Acknowledgment}

Yue Zheng and Zijian Gong contributed equally to this work as co-first authors.

\section{Funding}

There is no funding to report.

\section{Disclosure}

The authors report no conflicts of interest for this work.

\section{References}

1. Galván Casas C, Català A, Carretero Hernández G, et al. Classification of the cutaneous manifestations of COVID-19: a rapid prospective nationwide consensus study in Spain with 375 cases. Br J Dermatol. 2020;183(1):71-77. doi:10.1111/bjd.19163

2. Rothan HA, Byrareddy SN. The epidemiology and pathogenesis of coronavirus disease (COVID-19) outbreak. $J$ Autoimmun. 2020;109:102433. doi:10.1016/j.jaut.2020.102433

3. Huang C, Wang Y, Li X, et al. Clinical features of patients infected with 2019 novel coronavirus in Wuhan, China. Lancet. 2020;395 (10223):497-506. doi:10.1016/S0140-6736(20)30183-5

4. Carlos WG, Dela Cruz CS, Cao B, et al. Novel Wuhan (2019-nCoV) coronavirus. Am J Respir Crit Care Med. 2020;201(4):P7-P8. doi:10.1164/rccm.2014P7

5. Cheng ZJ, Shan J. 2019 Novel coronavirus: where we are and what we know. Infection. 2020;48(2):155-163. doi:10.1007/s15010-02001401-y

6. Guidance W. Clinical Management of Severe Acute Respiratory Infection When Novel Coronavirus (2019-Ncov) Infection is Suspected. WHO; 2020.

7. Recalcati S. Cutaneous manifestations in COVID-19: a first perspective. J Eur Acad Dermatol Venereol. 2020;34(5):e212-e213. doi: $10.1111 /$ jdv. 16387

8. Henry D, Ackerman M, Sancelme E, Finon A, Esteve E. Urticarial eruption in COVID-19 infection. J Eur Acad Dermatol Venereol. 2020;34(6):e244-e245. doi:10.1111/jdv.16472

9. Mahé A, Birckel E, Krieger S, Merklen C, Bottlaender L. A distinctive skin rash associated with coronavirus disease 2019? J Eur Acad Dermatol Venereol. 2020;34(6):e246-e247. doi:10.1111/ jdv. 16471

10. Kubanov AA, Deryabin DG. Skin manifestations in COVID-19 provide a clue for disease's pathophysiology understanding. J Eur Acad Dermatol Venereol. 2020. doi:10.1111/jdv.16902

11. Elmas ÖF, Demirbaş A, Özyurt K, Atasoy M, Türsen Ü. Cutaneous manifestations of COVID-19: a review of the published literature. Dermatol Ther. 2020;33(4). doi:10.1111/dth.13696

12. Marzano AV, Cassano N, Genovese G, Moltrasio C, Vena GA. Cutaneous manifestations in patients with COVID-19: a preliminary review of an emerging issue. Br J Dermatol. 2020;183(3):431-442. doi:10.1111/bjd.19264

13. Bouaziz JD, Duong T, Jachiet M, et al. Vascular skin symptoms in COVID-19: a french observational study. J Eur Acad Dermatol Venereol. 2020;34(9). doi:10.1111/jdv.16544 
14. Estébanez A, Pérez-Santiago L, Silva E, Guillen-Climent S, García-Vázquez A, Ramón MD. Cutaneous manifestations in COVID-19: a new contribution. J Eur Acad Dermatol Venereol. 2020;34(6):e250-e251. doi:10.1111/jdv.16474

15. Zengarini $\mathrm{C}$, Orioni G, Cascavilla A, et al. Histological pattern in COVID-19-induced viral rash. J Eur Acad Dermatol Venereol. 2020;34(9). doi:10.1111/jdv.16569

16. Diaz-Guimaraens B, Dominguez-Santas M, Suarez-Valle A, et al. Petechial skin rash associated with severe acute respiratory syndrome coronavirus 2 infection. JAMA Dermatol. 2020;156(7):820-822. doi:10.1001/jamadermatol.2020.1741

17. Magro C, Mulvey JJ, Berlin D, et al. Complement associated microvascular injury and thrombosis in the pathogenesis of severe COVID-19 infection: a report of five cases. Transl Res. 2020;220:1-13. doi:10.1016/j.trsl.2020.04.007

18. Young S, Fernandez AP. Skin manifestations of COVID-19. Cleve Clin J Med. 2020. doi:10.3949/ccjm.87a.ccc031

19. Otto MA. Skin manifestations are emerging in the coronavirus pandemic. Dermatology News; 2020. Available from: https://www. mdedge.com/dermatology/article/220183/coronavirus-updates/skin manifestations-are-emerging-coronavirus-pandemic. Accessed May $6,2020$.

20. Manalo IF, Smith MK, Cheeley J, Jacobs R. A dermatologic manifestation of COVID-19: transient livedo reticularis. $J$ Am Acad Dermatol. 2020;83(2):700. doi:10.1016/j.jaad.2020.04.018

21. Alramthan A, Aldaraji W. A case of COVID-19 presenting in clinical picture resembling chilblains disease. First report from the Middle East. Clin Exp Dermatol. 2020;45(6):746-748. doi:10.1111/ ced.14243CrossRefGoogleScholar
22. Cheng H, Wang Y, Wang GQ. Organ-protective effect of angiotensin-converting enzyme 2 and its effect on the prognosis of COVID-19. J Med Virol. 2020;92(7):726-730. doi:10.1002/ jmv.25785

23. Rico-Mesa JS, White A, Anderson AS. Outcomes in patients with COVID-19 infection taking ACEI/ARB. Curr Cardiol Rep. 2020;22 (5):31. doi:10.1007/s11886-020-01291-4

24. Català A, Galván-Casas C, Carretero-Hernández G, et al. Maculopapular eruptions associated to COVID-19: a subanalysis of the COVID-piel study. Dermatol Ther. 2020. doi:10.1111/dth.14170

25. Tatu AL, Nadasdy T, Bujoreanu FC. Familial clustering of COVID-19 skin manifestations. Dermatol Ther. 2020. doi:10.1111/ dth. 14181

26. Cepeda-Valdes R, Carrion-Alvarez D, Trejo-Castro A, HernandezTorre M, Salas-Alanis J. Cutaneous manifestations in COVID-19: familial cluster of urticarial rash. Clin Exp Dermatol. 2020;45 (7):895-896. doi:10.1111/ced.14290

27. Tatu AL, Nadasdy T, Nwabudike LC. Observations about sexual and other routes of SARS-CoV-2 (COVID-19) transmission and its prevention. Clin Exp Dermatol. 2020;45(6):761-762. doi:10.1111/ced.14274

28. Nadasdy T, Clatici VG, Barinova E, Tatu AL. Comments on does COVID-19 influence sexual behaviours? Dermatol Ther. 2020. doi:10.1111/dth.14083

\section{Publish your work in this journal}

Clinical, Cosmetic and Investigational Dermatology is an international, peer-reviewed, open access, online journal that focuses on the latest clinical and experimental research in all aspects of skin disease and cosmetic interventions. This journal is indexed on CAS.
The manuscript management system is completely online and includes a very quick and fair peer-review system, which is all easy to use. Visit http://www.dovepress.com/testimonials.php to read real quotes from published authors. 